\title{
Association Between Familial Mediterranean Fever and Cachexia in Females
}

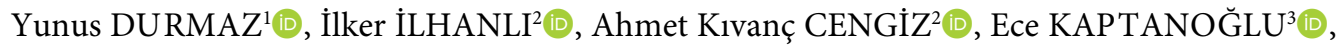 \\ Zekiye ÖZKAN HASBEK ${ }^{4}$, Sami HIZZMETLİ $\dot{I}^{5}$ \\ ${ }^{1}$ Department of Physical Medicine and Rehabilitation, Division of Rheumatology, Karabük Training and Research Hospital, Karabük, Turkey \\ ${ }^{2}$ Department of Physical Medicine and Rehabilitation, Division of Rheumatology, Ondokuz Mayıs University Faculty of Medicine, Samsun, Turkey \\ ${ }^{3}$ Department of Physical Medicine and Rehabilitation, Division of Rheumatology, Başkent University Zübeyde Hanım Application and \\ Research Center, Izmir, Turkey \\ ${ }^{4}$ Department of Nuclear Medicine, Cumhuriyet University Faculty of Medicine, Sivas, Turkey \\ ${ }^{5}$ Department of Physical Medicine and Rehabilitation, Division of Rheumatology, Cumhuriyet University Faculty of Medicine, Sivas, Turkey
}

\begin{abstract}
Objectives: This study aims to investigate the association between familial Mediterranean fever (FMF) and cachexia in females.

Patients and methods: The study included 32 female FMF patients (median age 27.50 years; range, 18 to 50 years) and 30 female healthy controls (median age 32 years; range, 18 to 50 years). Patients were classified according to Tel-Hashomer criteria. Circumference of arm, waist, and thigh was recorded. Short form 36 (SF-36) and Multidimensional Assessment of Fatigue (MAF) scale were applied. Composition of the body was measured with dual X-ray absorption. Muscle strength was measured with an isokinetic dynamometer, and strength of hand grip was measured from dominant hand with a hand dynamometer. C-reactive protein, erythrocyte sedimentation rate, fibrinogen and serum creatinine kinase (CK) levels were recorded.

Results: Body mass index was significantly higher in controls. Twelve patients and one control had cachexia. CK level was significantly higher in patients than controls. Mass of muscle without fat was significantly higher in patients than controls. Peak torque values of extension and flexion at the velocity of $60 \%$ second [Newton meter ( $\mathrm{Nm})$ ], and value of total work during extension at the velocity of $240 \%$ second ( $\mathrm{Nm}$ ) in isokinetic measures were significantly higher in controls. MAF score was significantly higher in patients with cachexia than patients without cachexia where the subscale scores of SF-36, except the vitality score, were significantly lower in patients with cachexia. However, Tel-Hashomer score was significantly higher in patients with cachexia.

Conclusion: This study pointed at a significant association between cachexia and FMF in females. Muscle endurance was not affected in FMF patients with cachexia; however, decreased muscle strength, impaired quality of life and increased fatigue were observed in these patients.

Keywords: Cachexia, familial Mediterranean fever, fatigue, muscle strength, quality of life.
\end{abstract}

Familial Mediterranean fever (FMF) is an autosomal recessive chronic disease characterized by repetitive abdominalgia and chest pain accompanying fever. Latterly, association of chronic inflammation in many inflammatory diseases, particularly in rheumatoid arthritis (RA), with body composition and cachexia is frequently studied. Chronic diseases such as infections including tuberculosis, cancer, acquired immune deficiency syndrome (AIDS), congestive heart failure, chronic obstructive lung disease, Crohn disease, and cystic fibrosis show the characteristics of cachexia as well as some elders without any chronic diseases. ${ }^{1}$ Although several diseases are being associated with cachexia, underlying pathophysiologic mechanisms are still

Received: May 20, 2019 Accepted: November 10, 2019 Published online: February 07, 2020

Correspondence: İlker İlhanlı, MD. Ondokuz Mayıs Üniversitesi Tıp Fakültesi Fiziksel Tıp ve Rehabilitasyon Anabilim Dalı, Romatoloji Bilim Dalı, 55280 Atakum, Samsun, Türkiye. Tel: +90 362 - 3121919 e-mail: ilkerilhanli@hotmail.com

Durmaz Y, Illhanlı I, Cengiz AK, Kaptanoğlu E, Özkan Hasbek Z, Hizmetli S. Association between Familial Mediterranean Fever and Cachexia in Females. Arch Rheumatol 2020;35(4):477-485. 
unclear. Cachexia is defined as a syndrome that emerges during other chronic diseases and characterized by loss of weight, loss of fat and accompanying loss of muscle by the increased protein catabolism. ${ }^{2,3}$ Cachexia is associated with increased mortality and morbidity. ${ }^{4}$ Cachexia is distinct from starvation, age-related loss of muscle mass, primary depression, malabsorption and hyperthyroidism and is associated with increased morbidity. ${ }^{1}$ Anker et al. ${ }^{5}$ has demonstrated that cardiac cachexia is associated with a poor prognosis, independently of functional severity, age, and exercise capacity and cardiac function. Inflammatory cytokines in FMF patients may change the body composition and lead to cachexia. Therefore, in this study, we aimed to investigate the association between FMF and cachexia in females.

\section{PATIENTS AND METHODS}

This study was conducted at Cumhuriyet University Faculty of Medicine between August 2013 and January 2014. The number of subjects was determined to be 30 to provide $80 \%$ of the research power. Thirty-two females with FMF (median age 27.50 years; range, 18 to 50 years) and 30 healthy females (median age 32 years; range, 18 to 50 years) were included in the study. Participants (i) $<18$ years old and $>50$ years old, (ii) without written consents, (iii) with chronic diseases and rheumatologic diseases other than FMF, (iv) who used corticosteroid within last year, (v) FMF patients who had malnutrition according to nutrition evaluation test, (vi) FMF patients who had disease duration of less than one year and (vii) those with acute episode were excluded. Patients were chosen and classified according to Tel-Hashomer criteria. ${ }^{6}$ Demographic data including age, occupation, smoking, duration after first diagnosis, delay time before first diagnosis, family history, dose of colchicines, and response to colchicines therapy (complete response: with no episode, incomplete response: $>50 \%$ decrease of the frequency of the episodes, no response: $<50 \%$ decrease of the frequency of the episodes or any response), frequency of the episodes (in a month), additional medications and accompanying diseases were recorded. 7 Symptom severity was scored by Tel-Hashomer and gene analysis for the mutation of MEFV was recorded. ${ }^{8}$ Circumference of arm, waist, and thigh was recorded in centimeters. Body mass index (BMI, in $\mathrm{kg} / \mathrm{m}^{2}$ and classified as slim, normal, overweight or obese) was calculated to evaluate the obesity while rate of the circumference of the waist to the thigh (WTR) was calculated to evaluate the central obesity. Both measures are frequently used to evaluate cardiovascular risks. ${ }^{9}$ Short form 36 (SF-36) for quality of life (QoL) and Multidimensional Assessment of Fatigue (MAF) scale were applied to both groups. ${ }^{10,11}$ Mass of skeletal muscles was measured with dual X-ray absorption (DXA with Hologic QDR 4500 W, Bedford, MA, USA) and mass of fat, muscle, and bone (for total body, and for arm, leg, and trunk separately) were recorded. Participants with a composition of fat less than $29 \%$ were accepted as cachexia. ${ }^{12}$ Muscle strength was measured from the dominant knee with an isokinetic dynamometer (Biodex Medical Systems, Shirley N.Y. 11967, USA). Peak torque value of flexion at the velocity of $60 \%$ second, peak torque value of extension at the velocity of $60 \%$ second, the value of total work during flexion at the velocity of $240 \%$ second and value of total work during extension at the velocity of $240 \%$ second were recorded (Figure 1). Strength of hand grip was measured from dominant hand with hand dynamometer (Saehan hydraulic hand dynamometer model SH5001, Masan, Korea). C-reactive protein (CRP, $\mathrm{mg} / \mathrm{L})$, erythrocyte sedimentation rate (ESR, $\mathrm{mm} /$ hour), fibrinogen $(\mathrm{mg} / \mathrm{dL})$ and serum creatinine kinase $(\mathrm{CK}, \mathrm{U} / \mathrm{L})$ levels were recorded. The study protocol was approved by the Cumhuriyet University Faculty of Medicine Ethics Committee. A written informed

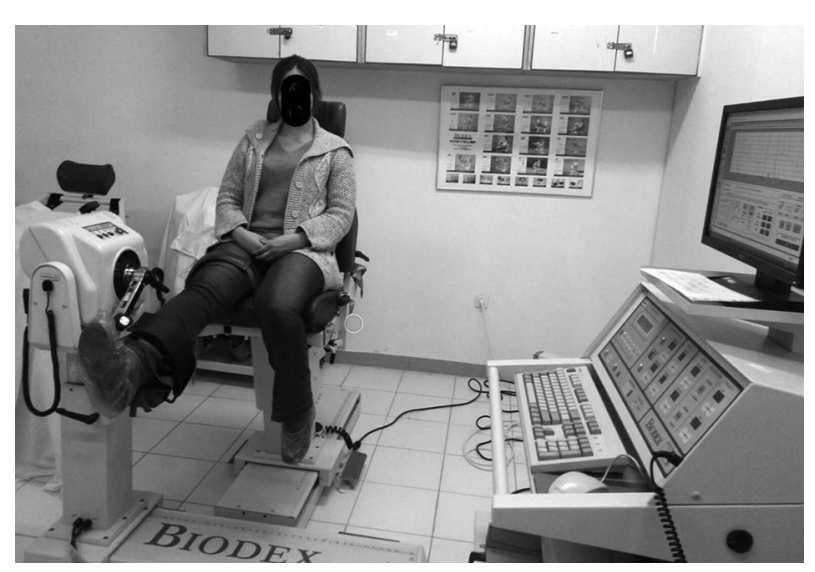

Figure 1. Measuring muscle strength by an isokinetic dynamometer. 
consent was obtained from each participant. The study was conducted in accordance with the principles of the Declaration of Helsinki.

\section{Statistical analysis}

Statistical analysis was performed using the SPSS version 14.0 software (SPSS Inc., Chicago, IL, USA). Kolmogorov-Smirnov test was used for comparing the means providing the assumption of normality and Mann-Whitney $U$ test was used for the means not providing the assumption of normality. $\mathrm{P}$ value $<0.05$ was considered statistically significant.

\section{RESULTS}

While four patients (12.5\%) were smokers, the number of smokers in controls was three (10\%). Twenty-three patients (71.9\%) had a family history of FMF, and all of them was under the treatment with colchicines, except one who was using canakinumab. Results of the anthropometric measures and the comparison of the patients and controls according to these measures are given in Table 1. According to the BMI, majority of the patients (68.8\%) had normal weight where majority of the controls were overweight or obese (56.7\%). Twelve patients (27.5\%) and one control (3.3\%) had cachexia, and prevalence of cachexia was significantly higher in patients than controls $\left(p=0.001, \chi^{2}=10.90\right)$.

$\begin{array}{ccc}\text { Patients' medians of } & \text { ESR, } \\ \text { CRP and fibrinogen were } 6.50\end{array}$
(range, 2-31) mm/hour, 3 (range, 1-10.9) mg/L, and 291 (range, 34-482) mg/dL, respectively, while these values were 5 (range, 2-22) $\mathrm{mm} /$ hour, 2 (range, 1-14) $\mathrm{mg} / \mathrm{L}$, and 295 (range, 209-441) mg/dL, respectively, in controls

Table 1. Anthropometric measures of participants, and comparison of FMF patients and healthy controls

\begin{tabular}{lccccccc}
\hline & \multicolumn{2}{c}{ FMF patients $(\mathrm{n}=32)$} & & \multicolumn{2}{c}{ Healthy controls $(\mathrm{n}=30)$} & \\
\cline { 2 - 3 } & Median & Min-Max & & Median & Min-Max & $p$ \\
\hline Height $(\mathrm{cm})$ & 160 & $150-172$ & & 163 & $145-175$ & 0.313 \\
Weight $(\mathrm{kg})$ & 55 & $40-95$ & & 67 & $53-98$ & $0.011^{*}$ \\
Body mass index $\left(\mathrm{kg} / \mathrm{m}^{2}\right)$ & 21.35 & $14.17-39.04$ & & 25.67 & $21.63-41.86$ & $0.022^{*}$ \\
Circumference of arm $(\mathrm{cm})$ & 25.50 & $21-43$ & & 30 & $24-38$ & $0.000^{*}$ \\
Circumference of waist $(\mathrm{cm})$ & 78 & & $58-110$ & & 87.50 & $67-130$ & 0.204 \\
Circumference of thigh $(\mathrm{cm})$ & 98 & & $77-125$ & & 110.50 & $95-130$ & $0.011^{*}$ \\
Circumference of the waist to the thigh & 0.81 & & $0.68-0.90$ & & 0.78 & $0.62-1.08$ & 0.313 \\
\hline
\end{tabular}

FMF: Familial Mediterranean fever; Min: Minimum; Max: Maximum; WTR: Circumference of waist/circumference of thigh; * Significance level: $\mathrm{p}<0.05$.

Table 2. Muscle strength and mass of muscle without fat, and comparison of FMF patients and healthy controls

\begin{tabular}{|c|c|c|c|c|c|}
\hline & \multicolumn{2}{|c|}{ FMF patients $(\mathrm{n}=32)$} & \multicolumn{2}{|c|}{ Healthy controls $(n=30)$} & \multirow[b]{2}{*}{$p$} \\
\hline & Median & Min-Max & Median & Min-Max & \\
\hline Strength of hand grip (kg) & 50 & $30-90$ & 50 & $35-82$ & 0.291 \\
\hline Peak torque value of extension at the velocity of $60 \% \mathrm{~s}(\mathrm{Nm})$ & 49.20 & $13.27-100.50$ & 62.80 & $24-104$ & $0.023^{*}$ \\
\hline Peak torque value of flexion at the velocity of $60 \% \mathrm{~s}(\mathrm{Nm})$ & 21.40 & $6-122$ & 29.50 & $11.8-58.5$ & $0.010^{*}$ \\
\hline Value of total work during extension at the velocity of $240 \% \mathrm{~s}(\mathrm{Nm})$ & 386.50 & $127-976.40$ & 522.75 & $318.50-1070$ & $0.022^{*}$ \\
\hline Value of total work during flexion at the velocity of $240 \% \mathrm{~s}(\mathrm{Nm})$ & 60 & $4.20-795$ & 77.85 & $8.5-408.5$ & 0.799 \\
\hline Mass of muscle without fat (gram) & 38,352 & $28,446-53,867$ & 42,704 & $33,174-56,190$ & $0.022^{*}$ \\
\hline Mass of muscle without fat of dominant arm (gram) & 1,844 & $1,265-2,735$ & $2,097.50$ & $1,257-3,254$ & 0.057 \\
\hline Mass of muscle without fat of dominant leg (gram) & $6,009.50$ & $4,507-9,995$ & 6,535 & $4,879-9,510$ & 0.111 \\
\hline
\end{tabular}


Table 3. Comparison of patients with and without cachexia according to anthropometric measures

\begin{tabular}{lccccc}
\hline Anthropometric measures & Presence of cachexia & $\mathrm{n}$ & Median & Min-Max & $p$ \\
\hline Height $(\mathrm{cm})$ & Yes & 12 & 161 & $155-168$ & 0.896 \\
& No & 20 & 159 & $150-172$ & \\
Weight $(\mathrm{kg})$ & Yes & 12 & 52 & $40-58$ & $0.000^{*}$ \\
& No & 20 & 64 & $48-95$ & \\
Body mass index $\left(\mathrm{kg} / \mathrm{m}^{2}\right)$ & Yes & 12 & 20.11 & $14.17-22.66$ & $0.000^{*}$ \\
& No & 20 & 24.71 & $18.75-39.04$ & \\
Circumference of arm $(\mathrm{cm})$ & Yes & 12 & 24.5 & $21-27$ & $0.000^{*}$ \\
& No & 20 & 27.75 & $22-43$ & \\
Circumference of waist $(\mathrm{cm})$ & Yes & 12 & 70 & $58-90$ & $0.002^{*}$ \\
\multirow{2}{*}{ Circumference of thigh $(\mathrm{cm})$} & No & 20 & 84.5 & $67-110$ & \\
& Yes & 12 & 91.5 & $84-100$ & $0.000^{*}$ \\
WTR & No & 20 & 104.5 & $77-125$ & \\
\hline Min: Minimum; Max: Maximum; WTR: Circumference of waist/circumference of thigh; * Significance level: $>0.05$. & $0.68-0.90$ & $0.002^{*}$ \\
Yes & No & 12 & 0.74 & $0.71-0.90$ &
\end{tabular}

Min: Minimum; Max: Maximum; WTR: Circumference of waist/circumference of thigh; * Significance level: $p<0.05$.

Table 4. Comparison of patients with and without cachexia according to duration after diagnosis, delay time of diagnosis, Tel-Hashomer, MAF and subscales of Short Form 36 scores

\begin{tabular}{|c|c|c|c|c|c|}
\hline & Presence of cachexia & $\mathrm{n}$ & Median & Min-Max & $p$ \\
\hline \multirow{2}{*}{ Duration after diagnosis (year) } & Yes & 12 & 5.5 & $3-16$ & \multirow{2}{*}{0.780} \\
\hline & No & 20 & 6 & $1-30$ & \\
\hline \multirow{2}{*}{ Delay time of diagnosis (year) } & Yes & 12 & 1 & $0-12$ & \multirow{2}{*}{0.780} \\
\hline & No & 20 & 1 & $0-9$ & \\
\hline \multirow{2}{*}{ Tel-Hashomer } & Yes & 12 & 5 & $4-11$ & \multirow{2}{*}{$0.001^{*}$} \\
\hline & No & 20 & 3 & $1-7$ & \\
\hline \multirow{2}{*}{ Multidimensional assessment of fatigue } & Yes & 12 & 40 & $20-50$ & \multirow{2}{*}{$0.001^{*}$} \\
\hline & No & 20 & 10 & $0-35$ & \\
\hline \multirow{2}{*}{ Physical function } & Yes & 12 & 32.50 & $30-55$ & \multirow{2}{*}{$0.001^{*}$} \\
\hline & No & 20 & 85 & $30-100$ & \\
\hline \multirow{2}{*}{ Physical role function } & Yes & 12 & 0 & $0-50$ & \multirow{2}{*}{$0.001^{*}$} \\
\hline & No & 20 & 50 & $0-100$ & \\
\hline \multirow{2}{*}{ Pain } & Yes & 12 & 22 & $22-40$ & \multirow{2}{*}{0.000} \\
\hline & No & 20 & 67 & $22-100$ & \\
\hline \multirow{2}{*}{ General health } & Yes & 12 & 17.50 & $15-92$ & \multirow{2}{*}{0.000} \\
\hline & No & 20 & 92.50 & $15-100$ & \\
\hline \multirow{2}{*}{ Vitality } & Yes & 12 & 30 & $15-35$ & \multirow{2}{*}{0.255} \\
\hline & No & 20 & 32.50 & $15-100$ & \\
\hline \multirow{2}{*}{ Social function } & Yes & 12 & 31.25 & $25-62.5$ & \multirow{2}{*}{$0.001^{*}$} \\
\hline & No & 20 & 43.75 & $25-100$ & \\
\hline \multirow{2}{*}{ Emotional role function } & Yes & 12 & 0 & $0-25$ & \multirow{2}{*}{0.000} \\
\hline & No & 20 & 66.70 & $0-100$ & \\
\hline \multirow{2}{*}{ Mental health } & Yes & 12 & 18 & $0-44$ & \multirow{2}{*}{$0.001^{*}$} \\
\hline & No & 20 & 44 & $12-100$ & \\
\hline
\end{tabular}




\begin{tabular}{|c|c|c|c|c|c|}
\hline & Presence of cachexia & $\mathrm{n}$ & Median & Min-Max & $p$ \\
\hline \multirow{2}{*}{ Strength of hand grip (kg) } & Yes & 12 & 47 & $30-60$ & \multirow{2}{*}{0.816} \\
\hline & No & 20 & 50 & $33-90$ & \\
\hline \multirow{2}{*}{$\begin{array}{l}\text { Peak torque value of extension at the } \\
\text { velocity of } 60 \% \mathrm{~s}(\mathrm{Nm})\end{array}$} & Yes & 12 & 31.80 & $13.27-56$ & \multirow{2}{*}{$0.003^{*}$} \\
\hline & No & 20 & 62.45 & $24.7-100.5$ & \\
\hline \multirow{2}{*}{$\begin{array}{l}\text { Peak torque value of flexion at the } \\
\text { velocity of } 60 \% \mathrm{~s}(\mathrm{Nm})\end{array}$} & Yes & 12 & 17.8 & 7.6-41 & \multirow{2}{*}{$0.013^{*}$} \\
\hline & No & 20 & 27.7 & $6-122$ & \\
\hline \multirow{2}{*}{$\begin{array}{l}\text { Value of total work during extension at } \\
\text { the velocity of } 240^{\circ} \mathrm{s}(\mathrm{Nm})\end{array}$} & Yes & 12 & 363.5 & $127-529$ & \multirow{2}{*}{0.061} \\
\hline & No & 20 & 414.5 & $146.4-976.4$ & \\
\hline \multirow{2}{*}{$\begin{array}{l}\text { Value of total work during flexion at the } \\
\text { velocity of } 240 \% \mathrm{~s}(\mathrm{Nm})\end{array}$} & Yes & 12 & 42.05 & $4.2-230$ & \multirow{2}{*}{0.061} \\
\hline & No & 20 & 83.1 & $9-795$ & \\
\hline \multirow{2}{*}{ Mass of muscle without fat (gram) } & Yes & 12 & 35,634 & $28,446-40,853$ & \multirow{2}{*}{$0.000^{*}$} \\
\hline & No & 20 & 41,518 & $30,421-53,867$ & \\
\hline \multirow{2}{*}{$\begin{array}{l}\text { Mass of muscle without fat of dominant } \\
\text { arm (gram) }\end{array}$} & Yes & 12 & 1,844 & $1,386-2,043$ & \multirow{2}{*}{0.477} \\
\hline & No & 20 & $1,848.50$ & $1,265-2,735$ & \\
\hline \multirow{2}{*}{$\begin{array}{l}\text { Mass of muscle without fat of dominant } \\
\text { leg (gram) }\end{array}$} & Yes & 12 & 5,663 & $4,507-6,077$ & \multirow{2}{*}{$0.002^{*}$} \\
\hline & No & 20 & 6,589 & $4,732-9,995$ & \\
\hline
\end{tabular}

( $p=0.308, p=0.115$, and $p=0.844$, respectively). CK level was significantly higher in patients than controls (98.50 [range, 35-291] U/L and 69 [range, 4-103] U/L, respectively, $\mathrm{p}=0.000$ ).

Medians of ESR, CRP, fibrinogen and $\mathrm{CK}$ were 8 (range, 2-30) $\mathrm{mm} /$ hour, 2.22 (range, 1-10.9) mg/L, 253(range, 154-370) mg/dL, and 87.50 (range, 51-150) U/L, respectively, in patients with cachexia while they were 6 (range, 2-31) mm/hour, 3 (range, 1-10.3) mg/L, 298 (range, 34-482) $\mathrm{mg} / \mathrm{dL}$, and 125.50 (range, 35-291) U/L, respectively, in patients without cachexia $(p=0.307, p=0.289, p=0.552$, and $p=0.209$, respectively). Heterozygote or homozygote M694V mutation was detected in four patients (12.5\%) with cachexia and in eight patients (37.5\%) without cachexia, with no significant difference $(p=0.992)$.

Table 2 shows the muscle strength and mass of muscle without fat, and the comparison of patients and healthy controls according to these variables.
Median age was 21 years (range, 18-40 years) for patients with cachexia and 36.50 years (range, 18-50 years) for patients without cachexia $(p=0.004)$. Comparison of patients with and without cachexia according to the anthropometric measures is given in Table 3. Comparison of patients with and without cachexia according to the duration after diagnosis, the delay time of diagnosis, Tel-Hashomer, MAF and subscales of SF-36 scores are given in Table 4. Comparison of patients with and without cachexia according to muscle strength and body composition is given in Table 5.

\section{DISCUSSION}

To our knowledge, this is the first study investigating the association between FMF and cachexia in females by examining the composition of the body as well as the muscle strength. Composition of the body varies between females and males, and we conducted the study in a homogeneous group of females. ${ }^{1}$ 
According to the anthropometric measures, there were no significant differences between patients and controls for height, circumference of waist and WTR, while weight, BMI, circumference of arm and thigh were significantly lower in patients than controls. Pamuk et al. ${ }^{13}$ conducted a study among FMF patients, and similar to our study, they did not find any difference in circumferences of waist between patients and controls; however, they did not evaluate the other anthropometric measures. Sarı et al. ${ }^{14}$ conducted a study among patients with ankylosing spondylitis (AS), and similar to our study, they did not find any difference between patients and controls according to the circumference of waist and WTR. ${ }^{14}$ Additionally, they did not detect any significant difference for BMI similar to the study of Rall et al. ${ }^{15}$ among patients with RA, and the study of Plasqui et al. ${ }^{16}$ among patients with AS.

In our study, prevalence of cachexia was higher in patients than healthy controls $(27.5 \%$ vs. $3.3 \%$, respectively). Although, to our knowledge, there is no clinical data in the literature for cachexia in patients with FMF, cachexia was reported in $10-67 \%$ of RA patients. ${ }^{2,4}$ We think that this variation of frequency is related to the methodological differences to detect cachexia. Frequencies of cachexia in other chronic diseases are 35\% for AIDS, 30\% for cancer, 20\% for chronic obstructive lung disease, $40 \%$ for renal failure, and $20 \%$ for heart failure. Frequency of cachexia in female FMF patients seems to be similar to that of other chronic diseases in the literature. ${ }^{17}$

Evaluation of the functional status of patients with rheumatologic diseases such as health-related QoL and muscle strength has great importance. Skeletal muscles are composed of type 1 muscle fibers that are slow oxidative fibers, gaining energy by the aerobic pathway, and they are important for endurance, while type 2 muscle fibers are fast glycolytic fibers, gaining energy by the anaerobic pathway, and providing fast and powerful contractions while getting tired in a short period. ${ }^{18}$ Meireles et al. ${ }^{19}$ studied both knees of RA patients and controls with isokinetic exercise machine and found significant decrease in patients for the values of total work during flexion and extension at the velocity of $300 \%$ second; however, they could not show any significant difference between patients and controls for the peak torque values of flexion and extension at the velocity of $60 \%$ second. In this study, the authors did not evaluate the composition of the body. In our study, peak torque values of extension and flexion at the velocity of $60 \%$ second, and value of total work during extension at the velocity of $240 \%$ second in isokinetic measures were significantly higher in controls where there was no difference for the value of total work during flexion. The main extensor of the knee is quadriceps femoris and it is composed of 55\% type 2 and 45\% type 1 muscle fibers. ${ }^{20}$ However, main flexors of the knee are hamstring muscles that are mainly composed of type 2 muscle fibers. ${ }^{21}$ Cachexia mainly affects the type 2 muscle fibers while usage of colchicines mainly affects type 1 muscle fibers. ${ }^{22,23}$ Usage of colchicines and having cachexia may affect both type 1 and 2 muscle fibers and lead to lower peak torque values of extension and flexion at the velocity of $60 \%$ second that show the muscle strength. The lower value of total work during extension, and an unaffected value of total work during flexion may be related to the different fiber type composition of extensor and flexor muscles of the knee. Also, we should keep in mind the small number of patients and different lifestyles of the subjects that may affect these results.

In a study conducted by Plasque et al. ${ }^{16}$ according to the mass of muscle without fat there was not significant difference between AS patients with FMF and controls. However, Marcora et al. ${ }^{24}$ found significantly lower mass of muscle without fat in male patients with AS similar to our study. Also, in this study, they detected positive correlation between mass of muscle and muscle strength. However, they did not find any significant difference between the AS patients and controls according to weight and BMI. Sar1 et al. ${ }^{14}$ and Sar1 et al. ${ }^{25}$ used bioelectrical impedance analysis to detect the composition of the body, and they could not find any significant difference between patients with FMF and controls according to the percent of fat and mass of fat. This difference from our study may be associated with the technique they used for detecting the composition of the body and not grouping the patients according to sex. Toussirot et al. ${ }^{26}$ did not find any difference for the mass of muscle without fat, the mass of fat, weight, and BMI between patients with AS and controls, 
and they attributed these results to excluding the patients with severe extra-articular disease. Also, they did not group the patients according to sex which may affect the results.

Muscaritoli et al. ${ }^{3}$ pointed to weight loss in patients with cachexia. Similar to this report, the average weight of FMF patients with cachexia was significantly lower than patients without cachexia. Furthermore, averages of BMI, circumference of arm, waist, and thigh, and WTR were significantly lower in FMF patients with cachexia than patients without cachexia. ${ }^{4}$ In the literature, we did not find any study evaluating the circumference of arm, waist, and thigh, which can discriminate rheumatologic patients with and without cachexia. Similar to our findings, Morley et al. ${ }^{4}$ reported lower weight and BMI in RA patients with cachexia. In contrast to this finding, Roubenoff ${ }^{27}$ and Walsmith et al. ${ }^{28}$ did not find any significant difference between RA patients and controls according to weight and BMI. These different results may be related to the different methodologies of the studies and conducting the studies for different diseases with variable subject numbers.

Duration and delay time of diagnosis in this study were similar to the literature, and there was no significant difference between the FMF patients with and without cachexia.

Fatigue is a frequent symptom among patients with rheumatologic diseases and impacts the health-related QoL. It is a subjective symptom and has no specific treatment, thus generally is not being considered in clinical practice. When we compared the FMF patients with and without cachexia, patients with cachexia had significantly higher MAF scores as well as higher Tel-Hashomer scores. Also, subscale scores of SF-36, except vitality, were significantly lower in FMF patients with cachexia than patients without cachexia, which may be the proof of the impacted healthrelated QoL.

In our study, peak torque values of extension and flexion at the velocity of $60 \%$ second in isokinetic measures were significantly lower in FMF patients with cachexia than patients without cachexia, which can be related to the affected type 2 muscle fibers. There was no difference for the value of total work during flexion and extension at the velocity of $240 \%$ second between patients with and without cachexia, which can be related to the unaffected type 1 muscle fibers during cachexia that is important for endurance. Marcora et al. ${ }^{24}$ reported significantly affected muscle strength of lower and upper extremities in AS patients with cachexia.

One of the differential features of cachexia is loss of weight both with loss of muscle mass without fat and loss of fat. In severe cachexia, as a result of drastic hypoalbuminemia, edema can emerge. In these cases, despite the severe cachexia, weight loss may not be seen. The same condition is noted in severe heart failure, cirrhosis, and renal failure. Continuous loss of skeletal muscle mass may cause loss of muscle strength, impaired respiratory function, general functional status and health-related QoL as well as disability. Loss of muscle mass is not specific for cachexia and may occur by starvation, malnutrition, aging, immobilization, sedentary lifestyle, and enervation. So, cachexia should be distinguished from other causes of loss of muscle mass leading to sarcopenia related to the aging. ${ }^{3}$ A majority of the clinical studies performed among patients with cancer, AIDS, congestive heart failure, severe renal failure, and RA showed similar findings to our study in terms of loss of muscle mass without fat and loss of fat. ${ }^{29-33}$

To our knowledge, there is no study in the literature evaluating the association of acute phase reactants with cachexia. In our study, there was no significant difference for acute phase reactants as well as the level of $\mathrm{CK}$ between FMF patients with and without cachexia. One should keep in mind that we excluded patients with an acute episode which can be the cause of these results. In patients with cancer fibrinogen, an acute phase reactant was found to be associated with cachexia and reported to be related to shorter survival. ${ }^{34}$ Also, Oranskiy et al. ${ }^{35}$ found a significantly higher level of interleukin 6 and adiponectin in RA patients with lower weight than patients with normal BMI.

There are studies that stated the association of M694V mutation with increased musculoskeletal symptoms in FMF patients. ${ }^{36}$ Sari et al. ${ }^{25}$ did not find any significant difference between FMF patients with M694V mutation and with mutations other than M694V for the rate of fat 
and muscle mass without fat. According to the M694V mutation, we did not find any significant difference between FMF patients with and without cachexia.

Limitations of this study include the selection bias, the lack of a male group and the small number of subjects. In generalizing these results to other populations, one should take into account the selection bias, the lack of a male group and the small number of subjects.

In conclusion, recognizing cachexia in patients with chronic inflammation has great importance, and physicians should be alert for early diagnosis. This study pointed at a significant association between cachexia and FMF. Muscle endurance was not affected in FMF patients with cachexia; however, decreased muscle strength, impaired QoL and increased fatigue were observed in these patients. This study showed that cachexia may impair the functional status of FMF patients. FMF patients with cachexia were slim and have lower values of the circumference of arm, waist, and thigh than patients without cachexia. Accordingly, an anthropometric evaluation may enable detecting patients at higher risk for cachexia.

\section{Declaration of conflicting interests}

The authors declared no conflicts of interest with respect to the authorship and/or publication of this article.

\section{Funding}

The authors received no financial support for the research and/or authorship of this article.

\section{REFERENCES}

1. Kotler DP. Cachexia. Ann Intern Med 2000;133:62234.

2. Evans WJ, Morley JE, Argilés J, Bales C, Baracos V, Guttridge D, et al. Cachexia: a new definition. Clin Nutr 2008;27:793-9.

3. Muscaritoli M, Anker SD, Argilés J, Aversa Z, Bauer $\mathrm{JM}$, Biolo G, et al. Consensus definition of sarcopenia, cachexia and pre-cachexia: joint document elaborated by Special Interest Groups (SIG) "cachexia-anorexia in chronic wasting diseases" and "nutrition in geriatrics". Clin Nutr 2010;29:154-9.

4. Morley JE, Thomas DR, Wilson MM. Cachexia: pathophysiology and clinical relevance. Am $\mathrm{J}$ Clin Nutr 2006;83:735-43.
5. Anker SD, Steinborn W, Strassburg S. Cardiac cachexia. Ann Med 2004;36:518-29.

6. Livneh A, Langevitz P, Zemer D, Zaks N, Kees S, Lidar T, et al. Criteria for the diagnosis of familial Mediterranean fever. Arthritis Rheum 1997;40:1879-85.

7. Talaat HS, Mohamed MF, El Rifai NM, Gomaa MA. The expanded clinical profile and the efficacy of colchicine therapy in Egyptian children suffering from familial Mediterranean fever: a descriptive study. Ital J Pediatr 2012;38:66.

8. Sohar E, Gafni G, Pras M. Tel Hashomer key to severity score for FMF. In: Proceedings of the First International Conference of FMF, September 1997. London and Tel Aviv: Freund Publishing House; 1997.

9. Seidell JC, Pérusse L, Després JP, Bouchard C. Waist and hip circumferences have independent and opposite effects on cardiovascular disease risk factors: the Quebec Family Study. Am J Clin Nutr 2001;74:315-21.

10. Ware JE Jr, Kosinski M, Keller SD. SF-36 physical and mental summary scales: a user's manual. Boston: The Health Institute, New England Medical Center; 1994.

11. Belza BL. Comparison of self-reported fatigue in rheumatoid arthritis and controls. J Rheumatol 1995;22:639-43.

12. Durnin JV, Womersley J. Body fat assessed from total body density and its estimation from skinfold thickness: measurements on 481 men and women aged from 16 to 72 years. Br J Nutr 1974;32:77-97.

13. Pamuk BO, Sari I, Selcuk S, Gokce G, Kozaci DL. Evaluation of circulating endothelial biomarkers in familial Mediterranean fever. Rheumatol Int 2013;33:1967-72.

14. Sari I, Demir T, Kozaci LD, Akar S, Kavak T, Birlik M, et al. Body composition, insulin, and leptin levels in patients with ankylosing spondylitis. Clin Rheumatol 2007;26:1427-32.

15. Rall LC, Walsmith JM, Snydman L, Reichlin S, Veldhuis JD, Kehayias JJ, et al. Cachexia in rheumatoid arthritis is not explained by decreased growth hormone secretion. Arthritis Rheum 2002;46:2574-7.

16. Plasqui G, Boonen A, Geusens P, Kroot EJ, Starmans $M$, van der Linden S. Physical activity and body composition in patients with ankylosing spondylitis. Arthritis Care Res (Hoboken) 2012;64:101-7.

17. Summers GD, Deighton CM, Rennie MJ, Booth $\mathrm{AH}$. Rheumatoid cachexia: a clinical perspective. Rheumatology (Oxford) 2008;47:1124-31.

18. Clamann HP, Broecker KT. Relation between force and fatigability of red and pale skeletal muscles in man. Am J Phys Med 1979;58:70-85.

19. Meireles SM, Oliveira LM, Andrade MS, Silva $\mathrm{AC}$, Natour J. Isokinetic evaluation of the knee in patients with rheumatoid arthritis. Joint Bone Spine 2002;69:566-73.

20. Guyton AC, Hall JE. Textbook of Medical Physiology. 11th ed. Philadelphia: Elsevier Saunders; 2006. p. 1061. 
21. Garrett WE Jr, Califf JC, Bassett FH 3rd. Histochemical correlates of hamstring injuries. Am J Sports Med 1984;12:98-103.

22. Wang Y, Pessin JE. Mechanisms for fiber-type specificity of skeletal muscle atrophy. Curr Opin Clin Nutr Metab Care 2013;16:243-50.

23. Kuncl RW, Bilak MM, Craig SW, Adams R. Exocytotic "constipation" is a mechanism of tubulin/lysosomal interaction in colchicine myopathy. Exp Cell Res 2003;285:196-207.

24. Marcora S, Casanova F, Williams E, Jones J, Elamanchi R, Lemmey A. Preliminary evidence for cachexia in patients with well-established ankylosing spondylitis. Rheumatology (Oxford) 2006;45:1385-8.

25. Sarı İ, Demir T, Can G, Akar S, Birlik M, Önen $F$, et al. Ailevi Akdeniz Ateşi Hastalarında vücut kompozisyonunun değerlendirilmesi. Fırat Tıp Dergisi 2009; 14: 181-5.

26. Toussirot E, Michel F, Wendling D. Bone density, ultrasound measurements and body composition in early ankylosing spondylitis. Rheumatology (Oxford) 2001;40:882-8.

27. Roubenoff R. Rheumatoid cachexia: a complication of rheumatoid arthritis moves into the 21st century. Arthritis Res Ther 2009;11:108.

28. Walsmith J, Abad L, Kehayias J, Roubenoff R. Tumor necrosis factor-alpha production is associated with less body cell mass in women with rheumatoid arthritis. J Rheumatol 2004;31:23-9.

29. Shike M, Russel DM, Detsky AS, Harrison JE, McNeill KG, Shepherd FA, et al. Changes in body composition in patients with small-cell lung cancer. The effect of total parenteral nutrition as an adjunct to chemotherapy. Ann Intern Med 1984;101:303-9.

30. Kotler DP, Wang J, Pierson RN. Body composition studies in patients with the acquired immunodeficiency syndrome. Am J Clin Nutr 1985;42:1255-65.

31. Toth MJ, Gottlieb SS, Goran MI, Fisher ML, Poehlman ET. Daily energy expenditure in free-living heart failure patients. Am J Physiol 1997;272:E469-75.

32. Mitch WE. Robert H Herman Memorial Award in Clinical Nutrition Lecture, 1997. Mechanisms causing loss of lean body mass in kidney disease. Am J Clin Nutr 1998;67:359-66.

33. Roubenoff R, Roubenoff RA, Cannon JG, Kehayias JJ, Zhuang H, Dawson-Hughes B, et al. Rheumatoid cachexia: cytokine-driven hypermetabolism accompanying reduced body cell mass in chronic inflammation. J Clin Invest 1994;93:2379-86.

34. Falconer JS, Fearon KC, Ross JA, Elton R, Wigmore $\mathrm{SJ}$, Garden OJ, et al. Acute-phase protein response and survival duration of patients with pancreatic cancer. Cancer 1995;75:2077-82.

35. Oranskiy SP, Yeliseyeva LN, Tsanaeva AV, Zaytseva NV. Body composition and serum levels of adiponectin, vascular endothelial growth factor, and interleukin- 6 in patients with rheumatoid arthritis. Croat Med J 2012;53:350-6.

36. Ben-Chetrit E, Backenroth R. Amyloidosis induced, end stage renal disease in patients with familial Mediterranean fever is highly associated with point mutations in the MEFV gene. Ann Rheum Dis 2001;60:146-9. 